\title{
Herd Homes: nutrient management and farmer perceptions of performance
}

\author{
R.D. LONGHURST ${ }^{1}$, J LUO ${ }^{1}$, M.B. O'CONNOR ${ }^{1}$ and T POW ${ }^{2}$ \\ ${ }^{1}$ AgResearch Ruakura, PB 3123, Hamilton \\ ${ }^{2}$ Wiremu Farms, Mata, RD1, Whangarei \\ bob.longhurst@agresearch.co.nz
}

\begin{abstract}
The recent invention of Herd Homes has presented NZ dairy farmers with a flexible facility for feeding and standing-off stock especially during wet periods. Herd Homes are a combination of feeding platform, stand-off facility and animal shelter comprising a "greenhouse" type roof over slatted concrete floors with an underfloor manure bunker. The prototype Herd Home built in Northland for 230 cows was closely monitored during its initial year (2002/03). Different bunker media were evaluated for their ability to absorb and retain manure nutrients. The media tested were natural materials (soil, wood shavings and a combination of soil/wood shavings) that were all effective at capturing nutrients $(\mathrm{N}$ and $\mathrm{S})$ from the bunker manure. Benefits of media amendments are greater nutrient enrichment of the final bunker manure making it more useful for subsequent land application. Use of soil as a bunker medium appears to be the most viable and cost effective option. In early 2006, manure samples were collected from Herd Home bunkers from four geographically diverse areas of NZ and analysed for nutrient content. Nutrient concentrations found reflected variability in cow numbers, usage and feed inputs. In November 2004, 10 existing Herd Home owners were surveyed as to their reasons for purchase. The farmers reported ease of farm management, "on-off" grazing, reduced pugging damage, and improved stock condition and production were some of the beneficial effects of Herd Homes.
\end{abstract}

Keywords: Herd Homes, winter management, wintering system, stand off, feed pad, manure management, bunker manure

\section{Introduction}

Herd Homes are a recent innovation in dairying and are a combination of feeding platform, stand-off facility and animal shelter. Covered feeding for stock takes place under a "greenhouse" type roof over slatted concrete floors. The Herd Homes (commonly referred to as 'sheds') are a standard $10 \mathrm{~m}$ wide but can vary in length from 48 to $60 \mathrm{~m}$. Cows stand on pre-stressed concrete slatted floors and their manure drops through the slats into a contained manure bunker below. Two rows of slats (3.5 m wide) run the length of the shed with a central panel to take the loading, creating two bunkers per shed. The bunkers can be lined with layers of natural materials, usually local topsoil or carbon-rich media (e.g. wood shavings, sawdust or pine bark) to absorb animal excreta so that no effluent discharge and little odour occurs.

The Herd Homes provide farmers with a viable management tool especially for protecting winter wet soils in high rainfall areas. Cows can be removed completely from pasture if necessary. The Herd Home concept has Regional Council support particularly in relation to effluent management, namely in converting from a liquid to a solid manure system for land application.

The prototype Herd Homes with twin $48 \mathrm{~m}$ long sheds were built at Mata by Northland farming couple, Tom and Kathy Pow, and finished in time for wintering 230 cows prior to the 2002/03 season. During 2003/04, Herd Homes were constructed in Northland and Southland and in Waikato and on the West Coast during $2004 / 05$. By the end of 2005/06 season approximately 20000 cows had access to Herd Homes.

In situ observations at the Mata sheds were carried out through the initial year to monitor the changes in moisture content and nutrient concentrations from the manure bunkers over time, and to evaluate different natural materials for their ability to absorb moisture, capture nutrients and control odour emissions. In November 2004, ten Herd Home owners were surveyed to learn why they had invested in Herd Homes and to record their perceptions from the initial year of operation. During early 2006, four sheds from different regions in NZ were emptied and bunker manures were sampled and chemically analysed for nutrient content.

\section{Evaluation of Different Bunker Media}

The first Herd Home comprised twin sheds (A and B). Cow numbers and time spent in the sheds during on-off grazing were monitored during the 2002 winter. Three of the four bunkers (each with surface area of $180 \mathrm{~m}^{2}$ ) were lined with different media materials to allow evaluation with a control bunker with raw manure only. The raw manure bunker allowed the accumulation of excreta deposition to be measured. The materials used were approximately $30.6 \mathrm{~m}^{3}$ of top soil (Waipu clay), $23.4 \mathrm{~m}^{3}$ of wood shavings and a mixture of both (12.6 $\mathrm{m}^{3}$ top soil and $16.2 \mathrm{~m}^{3}$ wood shavings). Some physical and chemical characteristics of the raw manure, wood 
Table 1 Some physical and chemical characteristics of raw manure, wood shavings and topsoil used as media in bunkers

\begin{tabular}{lccc}
\hline Measurement & Raw manure & Soil & Wood shavings \\
\hline Moisture (\%) & 85 & 33 & 30 \\
Bulk density $\left(\mathrm{t} / \mathrm{m}^{3}\right)$ & 1.01 & 0.94 & 0.14 \\
Carbon $(\%)$ & 5.8 & 4.6 & 51.0 \\
Nitrogen (\%) & 0.51 & 0.32 & 0.12 \\
C/N ratio & 11 & 14 & 425 \\
Phosphorus (\%) & 0.12 & 0.005 & 0.05 \\
Potassium (\%) & 0.52 & 0.001 & 0.10 \\
\hline
\end{tabular}

Table 2 Total depth of bunker profile (manure with absorbent media), dry matter (DM) content and nutrient concentrations in each manure bunker after 6 weeks and 9 months of use.

\begin{tabular}{|c|c|c|c|c|c|c|c|c|}
\hline Bunker media & $\begin{array}{l}\text { Depth } \\
(\mathrm{mm})\end{array}$ & $\begin{array}{l}\text { DM } \\
(\%)\end{array}$ & $\mathrm{N}$ & $\mathrm{P}$ & 6 in $\mathrm{DM}$ & $\mathrm{S}$ & $\mathrm{C}$ & $\begin{array}{r}\mathrm{C} / \mathrm{N} \\
\text { Ratio } \\
\end{array}$ \\
\hline 6 weeks & & & & & & & & \\
\hline Raw manure & 80 & 15 & 2.88 & 0.66 & 2.95 & 0.29 & 32.7 & 11 \\
\hline Soil & 170 & 45 & 0.53 & 0.14 & 0.30 & 0.08 & 6.6 & 12 \\
\hline Soil + WS & 250 & 38 & 0.67 & 0.21 & 0.48 & 0.11 & 14.2 & 21 \\
\hline Wood shavings & 130 & 19 & 1.88 & 0.43 & 1.56 & 0.25 & 57.5 & 31 \\
\hline 9 months & & & & & & & & \\
\hline Raw manure & 55 & 32 & 1.59 & 0.72 & 3.78 & 0.47 & 21.0 & 13 \\
\hline Soil & 170 & 64 & 0.82 & 0.29 & 0.62 & 0.15 & 9.2 & 11 \\
\hline Soil + WS & 230 & 57 & 0.57 & 0.17 & 0.54 & 0.11 & 13.3 & 24 \\
\hline Wood shavings & 170 & 33 & 1.73 & 0.50 & 2.79 & 0.41 & 42.8 & 25 \\
\hline
\end{tabular}

shavings and top soil are given in Table 1 . The fresh raw manure initially had a moisture content of $85 \%$,

Split spring/autumn calving is practised on the farm so cow numbers in milking/dry mobs were variable. During the 2002 winter, cows used the Herd Homes for a total of 84 days. Stock usage (number of cows by hours per day) in Shed A averaged 2,997 cow-days and 690 cow-days in Shed B. Total volume of accumulated manure for Sheds A and B was $43 \mathrm{~m}^{3}$ and $25 \mathrm{~m}^{3}$, respectively. Each bunker was sampled at 6 weeks and 3 months during stock usage and at 6 and 9 months after stock usage to monitor storage effects. Care was taken to get representative whole media profile samples from the same area each time using a hand trowel. Each $2 \mathrm{~kg}$ sample consisted of a composite of two profiles within each bunker.

Manure accumulated in height during the first 3 months when stock were using the sheds and then tended to decline in height while the dry matter content increased steadily with time (Table 2). In Northland as temperature increased, the bunker manures lost moisture and this continued during the hot summer. The soil bunker experienced the greatest reduction in moisture content, followed by the soil/wood shavings combination, wood shavings then raw manure. Moisture loss from the manures resulted in volume reduction and nutrient enrichment of the final product for land application.

\section{Nutrient content in media}

Samples of bunker manures with different media were analysed for dry matter (DM), nitrogen $(\mathrm{N})$, phosphorus $(\mathrm{P})$, potassium $(\mathrm{K})$, sulphur $(\mathrm{S})$ and carbon (C) by Gribbles E-lab The forms of $\mathrm{N}$ were also analysed. The nutrient contents of bunker manures, on a dry weight basis, are presented in Table 2 . Nitrogen concentrations of raw manure declined with time from $2.9 \%$ at 6 weeks to $1.6 \%$ at 9 months, while $\mathrm{N}$ in the soil bunker showed an increase from $0.5 \%$ to $0.8 \%$. Phosphorus concentrations in the soil bunker doubled during the same sampling period (from $0.14 \%$ to $0.29 \%$ ) whereas $\mathrm{P}$ increases in the other media were minimal. Potassium concentrations increased in all bunkers, doubling in the soil bunker from $0.30 \%$ to $0.62 \%$ and increasing markedly in the wood shavings bunker. Sulphur concentrations were enhanced in all bunkers except in the soil/wood shavings combination. Initially, the $\mathrm{C} / \mathrm{N}$ ratios in bunkers containing wood shavings (average 26) were about twice those of the raw manure and soil bunkers (average 12) and this trend remained after 9 months (Table 2). Chemical analysis of the initial raw manure found that ammonium-N contributed $12 \%$ and $3 \%$ of the total $\mathrm{N}$ in cow urine and dung (1:1 ratio) respectively. After 9 months, ammonium-N was still present in the raw manure and soil media, while it had largely been converted to nitrate$\mathrm{N}$ in the wood shaving medium probably because of 
Table 3 Forms of $\mathrm{N}$ in bunker manures after 9 months (numbers in brackets are percent of total $\mathrm{N}$ ).

\begin{tabular}{lcccc}
\hline Bunker manure & Total $\mathrm{N}$ & Ammonium-N & Nitrate-N & Organic N \\
\hline Raw Manure & 0.510 & $0.078(15)$ & $0.003(1)$ & $0.429(84)$ \\
Soil & 0.605 & $0.074(12)$ & $0.001(0)$ & $0.530(88)$ \\
$50 \%$ Soil+50\%WS & 0.347 & $0.009(3)$ & $0.063(18)$ & $0.274(79)$ \\
Wood shavings & 0.829 & $0.022(3)$ & $0.195(23)$ & $0.612(74)$ \\
\hline
\end{tabular}

Table 4 Changes in total amount of nutrients $(\mathrm{kg})$ in the manure bunkers (180 $\mathrm{m}^{2}$ surface area each) over time.

\begin{tabular}{llccc}
\hline Bunker Manure & Nutrients & After 3 months & After 6 months & After 9 months \\
\hline Raw manure & Nitrogen & 115.0 & 63.0 & 34.8 \\
& Sulphur & 15.3 & 12.4 & 10.3 \\
Soil & Nitrogen & 148.0 & 117.0 & 98.2 \\
& Sulphur & 20.0 & 21.0 & 18.0 \\
Wood shavings & Nitrogen & 194.0 & 39.0 & 64.0 \\
& Sulphur & 26.0 & 12.3 & 15.4 \\
Soil and wood shavings & Nitrogen & 235.0 & 84.0 & 78.0 \\
& Sulphur & 34.4 & 18.0 & 14.3 \\
\hline
\end{tabular}

nitrification activity in the wood shavings (Table 3 ). Organic $\mathrm{N}$ accounted for $74-88 \%$ of the total $\mathrm{N}$ in the bunker materials.

There was a similar trend in changes in nutrient contents over time in all bunkers. In the raw manure bunker, $\mathrm{N}$ and $\mathrm{S}$ declined by $70 \%$ and $33 \%$ respectively over 9 months (Table 4). The soil bunker showed the most promise for nutrient conservation with the lowest decline (10-34\%) in nutrients over time. The decline in nutrient amounts in wood shavings (42-67\%) and soil/ wood shavings combinations (59-67\%) were much greater than for the soil. These nutrient declines can be partly explained by gaseous losses.

\section{Gaseous emissions}

On three occasions, ammonia $\left(\mathrm{NH}_{3}\right)$ and hydrogen sulphide $\left(\mathrm{H}_{2} \mathrm{~S}\right)$ meters were used to monitor gaseous emissions from stirred manure in each bunker. Although total gas emissions cannot be quantified by this method, effects of the different bunker media on gaseous emissions can be compared. It appears that soil was the most effective bunker media for reducing $\mathrm{NH}_{3}$ and $\mathrm{H}_{2} \mathrm{~S}$ gaseous emissions. This correlates with soil having retained more $\mathrm{N}$ after 9 months in the bunker. The same effect with respect to the emission of $\mathrm{H}_{2} \mathrm{~S}$ and retention of $\mathrm{S}$ was also obtained by the addition of soil.

It should be noted that workers' safety should be seriously considered and protected, as these toxic gases, $\mathrm{NH}_{3}$ and $\mathrm{H}_{2} \mathrm{~S}$, could be emitted at high concentrations when the manure is moved out from the manure bunkers. There were no significant greenhouse gas $\left(\mathrm{N}_{2} \mathrm{O}\right)$ emissions released from the treated manure bunkers. Top soil appears to be the most viable and cost effective option for bunker media.

\section{Bunker manure comparison}

When four sheds in different regions were emptied, all with soil media, different factors that could affect nutrient composition (cow breed and size, supplementary feed type and amount, and intensity of shed use) were recorded (Table 5). Nutrient composition of the bunker manures reflected the variability resulting from differences in inputs (Table 6). Potassium tended to have the highest concentration in bunker manures presumably due to all the urine being contained and absorbed into the media. These analyses also confirm that $\mathrm{N}$ losses were occurring, as the ratio of $\mathrm{N}$ to $\mathrm{K}$ was close to 1.0 in raw manure (see Table 1) whereas the ratio was generally less than 1.0 at the time of emptying. The cows' diet, plus any feed additives like lime flour, magnesium or salt, will also have an effect on nutrient composition. These results illustrate the importance and need for farmers to analyse their own bunker manures in conjunction with nutrient budgeting so that appropriate fertiliser savings can be made when bunkers are emptied and the manures applied back onto land.

\section{Owners' Survey}

The 10 Herd Homes owners surveyed were either in Northland (6) or Southland (4) and represented a crosssection of different farming intensities. Although not all 10 owners had completed a full year of usage at the time of the survey, all had experienced the entire 2004 winter. However, there were insufficient data available for 
Table 5 Factors affecting inputs into bunker manure composition.

\begin{tabular}{|c|c|c|c|c|}
\hline & Northland & Waikato & West Coast & Southland \\
\hline Shed size $(m)$ & 48 & 51 & 54 & 48 \\
\hline Cow numbers & 180 & 85 & 180 & 150 \\
\hline Breed & Friesian & Holstein & Jersey & Ayrshire/Friesian \\
\hline Cow LWT (kg) & 450 & 500 & 400 & 375 \\
\hline Time $(\mathrm{h} / \mathrm{d})$ & 2.5 & 4 & 18 & 24 \\
\hline Usage (days/yr) & $365 \times 2$ & 365 & 120 & 90 \\
\hline Usage (\% year) & 15 & 25 & 25 & 25 \\
\hline Feed - silage & Grass, PK & Maize, PK & Grass, hay & Grass \\
\hline Feed - (kg DM/cow/d) & 15 & 18 & 10 & $8^{1}$ \\
\hline Manure - ht $(\mathrm{mm})$ & 1,200 & 600 & 650 & 1,200 \\
\hline Manure - vol $\left(\mathrm{m}^{3}\right)$ & 400 & 215 & 250 & 400 \\
\hline Manure BD (t/m³) & 1.02 & 1.04 & 0.83 & 0.92 \\
\hline
\end{tabular}

${ }^{1}$ Wintering rations:

$\mathrm{PK}=$ palm kernel

Table 6 Nutrient composition (kg/tonne) in bunker manures from different regions. Northland a = raw manure only, Northland $b=$ soil, both bunkers in same Herd Home.

\begin{tabular}{lccccccc}
\hline Region & $\mathrm{N}$ & $\mathrm{P}$ & $\mathrm{K}$ & $\mathrm{S}$ & $\mathrm{Ca}$ & $\mathrm{Mg}$ & $\mathrm{Na}$ \\
\hline Northland a & 5.7 & 2.2 & 9.2 & 1.3 & 6.6 & 2.3 & 1.5 \\
Northland b & 8.8 & 2.6 & 11.3 & 1.3 & 11.3 & 2.7 & 1.5 \\
Waikato & 4.8 & 1.1 & 7.2 & 0.6 & 2.5 & 1.5 & 1.1 \\
West Coast & 5.7 & 1.3 & 4.6 & 0.6 & 2.8 & 1.4 & 0.7 \\
Southland & 4.6 & 0.6 & 4.8 & 0.6 & 0.9 & 1.5 & 1.1 \\
\hline
\end{tabular}

comparative milk production figures. The survey found that the main reason for buying the Herd Homes was related to farm management. Perceived benefits listed were "peace of mind", having somewhere to put the herd in wet weather or during periodic flooding. Feeding out was also much easier (being similar to using a feed pad) and not having to feed stock in mud and wasting feed on paddocks were seen as benefits. Less wintering feed was required for stock, e.g., three Southland farmers reported feeding $12-14 \mathrm{~kg} \mathrm{DM} / \mathrm{cow} /$ day in paddock versus $8-9 \mathrm{~kg} \mathrm{DM} / \mathrm{cow} /$ day in Herd Home. Time was saved by $90 \%$ of farmers and farm management aided by not having to cart silage around the farm or having to clean yards after standing cows off. The second reason revolved around grazing management issues. Cows were moved from pastures either frequently $(30 \%)$ or at every opportunity $(60 \%)$ to protect wet soils and limit pugging damage. Most farmers (60\%) reported at least $20 \%$ more pasture being saved, and had noted better pasture composition, more control of grazing and the ability to build up a feed bank. Farmers reported stock management as the third benefit by finding that the Herd Homes could be used for other purposes besides feeding (90\%). These included calving, viewing stock condition and drafting, as well as using as a stand-off area. One farmer used the sheds for feeding yearlings.
Most farmers (90\%) reported greater improvements in cow condition since using the Herd Homes compared to beforehand. These farmers reported that average herd cow condition scores were likely to improve by at least 0.5 . Stock also tended to be quieter and more content.

Because most farmers had not yet experienced a full year with the sheds it was difficult to accurately compare stock health issues. Farmers who calved in the sheds commented that, because the cows were in such good condition, larger calves were being born which required more cow assistance. Care was required with smaller Jersey calves getting their feet stuck in the grating. The addition of hay on the slats overcame this potential problem.

All farmers reported that the Herd Homes performed to their expectations and that farm management was now easier as more options were available. The farmers and farm staff found that life was less stressful and wintering was no longer a chore. The cows quickly adapted to using the sheds and showed a preference for staying in them rather than grazing in paddock during wet or cold spells.

In conclusion all farmers surveyed regarded Herd Homes as a successful addition to their farm management. Cows were perceived to be contented and were well fed. Use of Herd Homes improved pasture 
productivity and it is important that this extra growth is utilised to increase milk production or improve stock condition.

\section{ACKNOWLEDGEMENTS}

Brian Hunt for technical support in Northland and Herd Homes owners for their assistance. 